\title{
Training of intensive care nurses to handle continuous hemodialysis: a latent condition for safety
}

\author{
Formação dos enfermeiros intensivistas para manejar hemodiálise contínua: condição latente à segurança
}

Formación de los enfermeros intensivistas para manejar la hemodiálisis continua: una condición latente de la seguridad

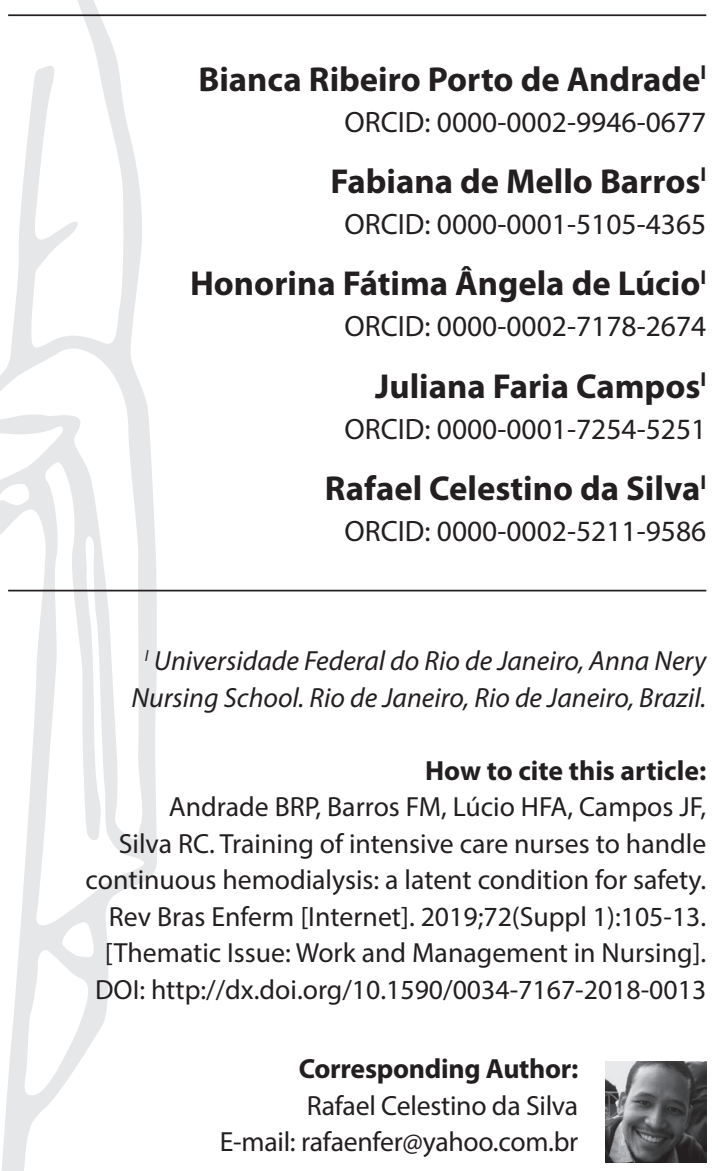

Submission: 01-10-2018
Approval: 03-28-2018

\begin{abstract}
Objective: To analyze the repercussions of the training of nurses working in the Intensive Care Unit for the management of continuous hemodialysis regarding the safety of critical patients with acute renal failure. Method: Qualitative research developed considering James Reason's reference in the Intensive Care Unit of a private hospital. The data was collected with 23 nurses who worked for more than three months in the management of continuous hemodialysis through a semi-structured interview, and analyzed with the thematic content analysis technique. Results: There are weaknesses in the training of intensive care nurses for the management of continuous hemodialysis that become a latent failure. Such a failure results in difficulties in handling hemodialysis, with risks for these professionals to commit active failures. Final considerations: The training program in service for the management of continuous hemodialysis must be perfected, to develop skills and competencies in nurses and improve their performance. Descriptors: Intensive Care; Patient Safety; Nursing; Renal Dialysis; Biomedical Technology.
\end{abstract}

\section{RESUMO}

Objetivo: Analisar as repercussões da formação de enfermeiros que atuam em Unidade de Terapia Intensiva para o manejo da hemodiálise contínua tendo em vista a segurança do paciente crítico com injúria renal aguda. Método: Pesquisa qualitativa, desenvolvida à luz do referencial de James Reason na Unidade de Terapia Intensiva de hospital privado. Os dados foram coletados com 23 enfermeiros que atuavam há mais de três meses no manejo da hemodiálise contínua através de entrevista semiestruturada, e analisados com a técnica de análise de conteúdo temático. Resultados: Há fragilidades na formação de enfermeiros intensivistas para o manejo da hemodiálise contínua que se configuram numa falha latente. Tal falha resulta em dificuldades no manuseio da hemodiálise, com riscos de esses profissionais cometerem falhas ativas. Considerações finais: É preciso aperfeiçoar o programa de treinamento em serviço para o manuseio da hemodiálise contínua, para desenvolver no enfermeiro habilidades e competências e melhorar sua performance.

Descritores: Cuidados Intensivos; Segurança do Paciente; Enfermagem; Diálise Renal; Tecnologia Biomédica.

\section{RESUMEN}

Objetivo: Analizar las repercusiones de la formación de enfermeros que actúan en Unidades de Terapia Intensiva para el manejo de la hemodiálisis continua teniendo en vista la seguridad del paciente crítico con lesión renal aguda. Método: Investigación cualitativa, desarrollada bajo la luz del referencial de James Reason en la Unidad de Terapia Intensiva de un hospital privado. Los datos fueron recolectados con 23 enfermeros que actuaban hacía más de tres meses en el manejo de la hemodiálisis continua a través de entrevista semiestructurada, y analizados con la técnica de análisis de contenido temático. Resultados: Hay fragilidades en la formación de enfermeros intensivos para el manejo de la hemodiálisis continua que se configuran en una falla latente. Esa deficiencia resulta en dificultades en el manejo de la hemodiálisis, con riesgo de que estos profesionales cometan fallas activas. Consideraciones finales: Es necesario perfeccionar el programa de entrenamiento en servicio para el manejo de la hemodiálisis continua, para desarrollar en los enfermeros habilidades y competencias y mejorar su desempeño.

Descriptores: Cuidados Intensivos; Seguridad del Paciente; Enfermería; Diálisis Renal; Tecnología Biomédica. 


\section{INTRODUCTION}

Continuous hemodialysis $(\mathrm{CH})$ is a treatment that removes fluids and waste from hemodynamically unstable patients continuously and is a widely used therapeutic option in the Intensive Care Unit (ICU) for patients with acute renal failure ${ }^{(1-2)}$. Its advantages include efficiency to control uremia, hypophosphatemia, hyperkalemia and metabolic acidosis; the physiological form the treatment occurs; the safety it provides for patients with brain injuries and cardiovascular diseases; the possibility of being an adjunctive therapy in sepsis; and the likelihood of renal recovery ${ }^{(1)}$.

It is, therefore, a method that purifies blood in relation to the endogenous and exogenous toxins retained in a continuous and uninterrupted manner, promoting acid-base balance, electrolytic and volume ${ }^{(3)}$. The frequency of $\mathrm{CH}$ in critical patients is visualized in the data that up to $70 \%$ of patients with acute renal failure receive intermittent or continuous renal replacement therapy, with continuous $\mathrm{CH}$ being the most common in those with instability ${ }^{(4)}$.

The indication of $\mathrm{CH}$ modalities depends on the nephrological condition and the clinical status of patients, which may be: Slow Continuous Ultrafiltration (SCUF), Continuous Venovenous Hemofiltration (CVVH), Continuous Veno-venous Hemodialysis (CVVHD) and Hemodiafiltration, (CVVHDF). The CVVHDF is the most used modality in the ICU, combining the process of blood purification by diffusion and convection through a membrane with high permeability. Blood and dialysis fluid circulate as in hemodialysis, but because of the high degree of water loss it is necessary to use the replacement fluid to achieve adequate fluid balance ${ }^{(5)}$.

Nurses contribute significantly to the application of $\mathrm{CH}$ in $\mathrm{ICU} s^{(6-}$ ${ }^{7)}$. One of the models adopted by some institutions to organize Nursing care in continuous hemodialysis is the collaborative one, which counts on the participation of a nephrologist nurse and an ICU nurse in the conduction of this therapy ${ }^{(6)}$. In these cases, the importance of the preparation and continuous training of the ICU professional is highlighted, in view of the safety of critical patients.

This is because, in this model, the professional prepares the circuit of the machine, connecting it to the vascular catheter of the patient and performs treatment maintenance tasks: adjustment in the fluid configurations to provide fluid balance; electrolyte monitoring and acid-base balance of the patient; alarm verification; diagnosis of circuit coagulation and its disconnection from the patient ${ }^{(7)}$. Nurses of the dialysis units are also in charge of this process.

Therefore, ICU nurses must acquire new skills specific to the handling of $\mathrm{CH}$. The relevance of their abilities is corroborated in the literature. Research on Nursing practices during continuous hemodialysis in Italian hospitals found that $45 \%$ of those who handled it had no specific training and had acquired expertise during work. In addition, $62 \%$ of dialysis workers received training for $\mathrm{CH}$, whereas $34 \%$ of ICU nurses participated in a training program $^{(8)}$.

An investigation examined Nursing practices in continuous hemodialysis in Canadian ICUs regarding demographic data, vascular access, filters, adverse events, training, anticoagulation, and onset of $\mathrm{CH}$. Of the 73 instruments answered by those responsible for Nursing education, the greatest concern was training the staff and their competences for handling $\mathrm{CH}$, since not all of them had took part in consistent training programs ${ }^{(4)}$.
Thus, these evidences point out that there are challenges for ICU nurses to achieve and sustain proficiency in handling continuous hemodialysis. One of the reasons is that this activity represents only part of its practice, which generates less motivation for qualification and research initiatives, with the responsibility of providing support to ICU nurses to play their best roles ${ }^{(9)}$.

Despite the model in which specialist nurses in nephrology of the unit of dialysis in hospitals or specialized clinics are the protagonist in conducting the therapy still be adopted in many contexts, the advantages of ICU nurses to know the conditions of a patient, their approach and their abilities in the management of equipment have led institutions to opt for their participation in continuous hemodialysis, which is the case here, that adopts the collaborative model.

Considering that, we must reflect on the safety of the ICU nurse's performance in relation to critical patients, especially when considering the existence of studies performed in hemodialysis units that have already indicated a high prevalence of adverse events in patients submitted to the hemodialysis process, as well as their correlation with the professional's training.

This is the case of research that estimated and analyzed the prevalence of adverse events related to $\mathrm{CH}$ by the documentary analysis of 117 records of a $\mathrm{CH}$ unit. The occurrence of 1,272 adverse events was detected in 94 charts, which is equivalent to a prevalence of $80 \%$. The frequency distribution was inadequate blood flow (40\%); bleeding from venous access devices (11\%); infection (9\%); system coagulation (7\%); and equipment failure (5\%). Concerning damage, $76 \%$ were mild, $22 \%$ moderate and $0.9 \%$ severe $^{(10)}$.

Also in the reports of 25 professionals of the Nursing team of the dialysis unit of a teaching hospital, 517 adverse events were detected, with the highest occurrences related to central venous access (28\%) and equipment (14.5\%). The causes were linked to the patient, 18 of them due to their clinical condition; to the professional, in 172 cases for individual failures, besides the lack of training; and to the organization of the service, due to inadequate material resources and equipment, work overload, lack of training and water supply ${ }^{(11)}$.

These results from studies developed in specialized $\mathrm{CH}$ units gain even greater relevance when one thinks of the continuous dialysis performed in critical ICU patients, who are prone to adverse events. The Resolution of the Collegiate Board (Resolução da Diretoria Colegiada) No. 11/2014, which provides for good practices in the functioning of dialysis services, establishes that these services need to identify situations of risk to patient safety and develop strategies to prevent incidents ${ }^{(12)}$.

Therefore, it is considered that in the case of continuous hemodialysis made with the participation of ICU nurses, their training is a latent condition that can imply in safety incidents. Given that, the question was: how does the training of ICU nurses to manage the $\mathrm{CH}$ and what repercussions do they have in the safety of their performance before the critical patient who uses such technology?

\section{OBJECTIVE}

To analyze the repercussions of the training of nurses working in the Intensive Care Unit for the management of continuous hemodialysis regarding the safety of critical patients with acute renal failure. 


\section{METHOD}

\section{Ethical aspects}

Research was approved by the Research Ethics Committee of the Nursing School Anna Nery (Comitê de Ética em Pesquisa da Escola de Enfermagem Anna Nery) and the co-participant of the study. The nurses who agreed to participate signed the Free and Informed Consent Form in two copies, being in possession of one of them, and were identified by the code C=Participant, followed by their enrollment number.

\section{Type of study and theoretical reference}

A qualitative exploratory-descriptive study was carried out in a private hospital in the city of Rio de Janeiro from June to October 2016. Reason's theoretical perspective was applied, which seeks to know the processes that contribute to human error in attempting to apply this knowledge in practice through the creation of mechanisms to contain the harmful effects of error. The defense is that the analysis of errors in health care is not only the error of people who act directly at the tip of the system (active failures), but must take into account the underlying conditions that made it possible. It starts from the premise that human beings are fallible and that these errors are therefore expected within the system, thus bringing the concept of latent error, which is an avoidable action within the system, based on managers' decisions. Hence, there are latent failures in the system that, at any given time, can leave the latency condition and result in active errors. In the present study, this understanding will be used to analyze the links of training ICU nurses (latent condition) with the safety of their performance in the management of continuous hemodialysis applied ${ }^{(13-14)}$.

\section{Methodological procedures}

\section{Field and data source}

The place studied was ICU of this institution, which concentrates 26 beds, subdivided into three environments according to the degree of severity of patients, namely: the ICU of the $1^{\text {st }}$ floor, which centralizes the most critically ill, hemodynamically unstable patients; the ICU of the $2^{\text {nd }}$ floor, intended for hemodynamically stable patients who still require intensive care; and ICU 1, for patients in the transition phase for care in wards.

Continuous hemodialysis occurs more frequently in patients hospitalized in the ICU of the 1st floor. On average, in this subunit, there are 2.45 continuous daily sessions of $\mathrm{CH}$, approximately 76 sessions per month. Therefore, the patients are adults, with high severity and hospitalization due to varied clinical conditions. Equipment used in the setting investigated is by brand Gambro, called PrismaFlex, which is intended for continuous renal replacement therapy for patients with acute renal failure and/or fluid overload. It is easy to use, with advanced software, which has a good data interface for users, as well as interactive alarm systems.

The collaborative model in the institution is composed of nurses who work in the ICU, on a 12-hour shift and 36-hour rest, and are responsible for the planning, introduction, maintenance and follow-up of this therapy; and nurses of nephrology who, in the case of the unit, are nurses of the ICU itself, with theoretical and practical experience in the management of $\mathrm{CH}$ and act as reference in clarifying doubts and problem solving, managing the hemodialysis process. In addition, the model integrates the medical team, who is responsible for the prescription of continuous hemodialysis.

The inclusion criteria to participate in research were: to be an ICU nurse; act in the direct care to critical patients submitted to $\mathrm{CH}$; be active in the sector during the data production period; and have more than three months of performance in the unit. This is because the professional newly hired in the research institution undergoes a three-month training period, acting in a supervised manner. The exclusion criterion was to be an ICU nurse responsible for continuous hemodialysis management.

When nurses are admitted to this institution, they work in the day shift during the first three months to know the routine procedures and activities of the allocation sector, as well as to perform the recommended training. In the case of $\mathrm{ICU}$, the performance of professionals is supervised by two nurses during this period, one involved with direct patient care, and another considered a reference in the daily activities of the sector. At this stage, one of the professional improvement courses is handling continuous hemodialysis.

To capture nurses who met the inclusion criteria, the researcher was included in the field of research, to conduct an exploratory stage after the approval of the project by the Research Ethics Committee of the institution. At this stage, the researcher was immersed in the field for approximately two months to become familiar with the reality being studied, approaching nurses and explaining about research, and inviting those who met the inclusion criteria to participate. This immersion also made it possible to take notes in a field diary of generic characteristics of the activities developed by nurses during the handling of $\mathrm{CH}$, captured by observation, that could help in the analysis of data.

\section{Collection, organization and analysis of data}

The selected nurses who agreed to participate in the study were taken to a room at which the interviews were conducted, depending on their availability during the shift. A semi-structured script was constructed based on a review of literature, which pointed to the need for specialized knowledge and nurses' education; management of therapy; Nursing care with patients, the machine and the $\mathrm{CH}$ circuit; complications; and the use of protocols $s^{(7,15)}$.

This script had a part for characterization of the participants' professional data and another for exploration of the object, whose issues alluded to their performance, difficulties faced, received training, education and safety incidents. The interviews lasted 30 minutes and were recorded with an MP4 device. These interviews were transcribed and then underwent a content review for the detection of transcription errors.

For the analysis of data the thematic content analysis technique was applied, developed through the following stages: in the first stage, a floating reading of the corpus of interviews was performed, in which a general impression was obtained on information that its content carried; in the second, the entire corpus of thematic registration units $(R U)$ was carried out, which sought the themes addressed by participants; in the third, these identified themes 
were put together according to their meaning, giving rise to units of meaning. These units of meaning, composed of themes, were transposed into a spreadsheet, which recorded the appearance of these themes in each interview and their frequency ${ }^{(16)}$.

This strategy made it possible to track the appearance of new topics in interviews. Thus, the theoretical saturation criterion ${ }^{(17)}$ was used to decide on the finalization of data production. In the $18^{\text {th }}$ interview, the repetition of themes was detected, and 5 further interviews were carried out, which did not demonstrate the addition of new elements, allowing the theoretical densification needed to meet the proposed objectives. Thus, the corpus consisted of 23 interviewees, of both sexes, considering the potential number of 49 participants.

The fourth stage was that of categorization, where the units of meaning and their respective number of thematic $\mathrm{RU}$ and their percentage frequency were recorded separately in a second worksheet. This initial separation led to the analysis of the units of meaning according to the semantic criterion, in view of the objectives of research and the theoretical perspective of analysis of errors that differentiate them in latent and active ${ }^{(13-14)}$, which made possible to make the inferences. The analysis allowed the regrouping of the units of meaning into two categories, namely: 1 - Latent security situation: academic and professional training for the management of continuous hemodialysis; 2 - Performance in the management of continuous hemodialysis: difficulties and risks of active failures.

\section{RESULTS}

Regarding the profile of people interviewed: $82 \%$ are women, ranging from $30-40$ years old (43\%); $65 \%$ of participants are not ICU specialists; $39 \%$ have up to 5 years of training and $38 \%$ between 5 and 10 years; $56 \%$ have been in the field for 5 years.

\section{Latent condition to safety: academic and professional training for managing continuous hemodialysis}

The theme of the training of nurses for the management of $\mathrm{CH}$ obtained $57 \mathrm{RU}$. Of these, 11 referred to training related to the knowledge acquired in the scope of undergraduate and graduate education. These $\mathrm{RU}$ show the lack of approach to this theme of continuous hemodialysis in academic training, as observed in the following excerpts:

Actually, we are not trained during university, graduate school and specializations to work with Prisma. (C9: more than 10 years of education, more than 10 years in the industry, specialist in ICU)

I had never heard about it during university, that part of dialysis was seen fast in undergraduate, we were said that we had the training [...] but they did not explain. When I came to work here, I discovered and learned about it, which made my life easier, in my specialization, because it gave me knowledge, but the knowledge I had of dialysis and Prism here is much larger than the knowledge from undergraduate. So, totally different from what I had already heard, that in fact I had not heard anything [...]. (C7: up to 5 years of training, up to 5 years in the sector, not an ICU specialist)

This lack of previous training to subsidize care of patients in the use of continuous hemodialysis results in the report of Nursing
15 , with 1 year and 10 months in the sector, who is concerned with the education of nurses and their risks to patient safety.

Working with dialysis is not the same thing as helping the doctor with a deep puncture, it's not the same as helping the doctor with a mean blood pressure (MBP) [...] It involves a lot of things with patients, with their lives [...] I will be really honest, my fear is of doing something thinking that I am doing right and I do it wrong and harm the patient, and end up being charged as if I had the training needed to perform such procedure. (C15: from 5-10 years of training, up to 5 years in the sector, specialist in ICU)

The remaining $46 \mathrm{RU}$ were related to in-service training, addressing the theme of training and its relevance to nurses' performance in the management of continuous hemodialysis. In this sense, the researchers evaluate the frequency, nature and quality of the training received. Concerning quality, there was a greater tendency for positive evaluation, because of the knowledge of instructors and the opportunity to handle equipment prior to contact with patients.

The trainings are very good because a lot of our knowledge we learned here with our managers, our leaders and the outsiders, who are also qualified. The knowledge we received came from very trustable sources, from a staff that has mastered the system. It was a good learning, a good use. (C10: more than 10 years in the field, more than 10 years of training, not an ICU specialist)

I cannot complain about the training, when I came in here I received aCD that explained the whole process, how everything worked, and I already did two Prisma training sessions. So, I cannot complain about this part, I received two trainings and one more Cd. (C3: up to 5 years of training, up to 5 years in the field, specialist in ICU)

On the other hand, training is also questioned by nurses. One of the questions asked is the time between these trainings, given the nurses' turnover and the frequency in which there is a patient in the sector using $\mathrm{CH}$, which can be a factor that generates doubts about the care of this patient.

The training must be a continuous factor, it is no use doing training today and tomorrow a new person arrives, and the one who had training leaves the shift. It has to be something continuous and even daily, imagine the patient there doing $\mathrm{CH}$ and new people arrived; or until a nurse who is there for a long time has questions, and has to call the nurse from the routine, or waiting to receive training there with the staff, we cannot leave questions unanswered. (C18: up to 5 years in the field, up to 5 years of training, not an ICU specialist)

A bit of insecurity, yes, it joins the training that I would like it to be constant because I had the training, they trained me, but it was when lentered here, now / wanted another one because it is not something that we always have, as we change sectors, sometimes I'm in sectors for less than two months, in a sector that I'm not a part of, it's a matter of insecurity, training and a bit of knowledge as well. (C7: up to 5 years of training, up to 5 years in the sector, not an ICU specialist)

Interviewee 7 indicates that there is rotation in the allocation of nurses in the three subunits of the ICU. As in the ICU of the $1^{\text {st }}$ floor, 
it is more frequent to have patients in $\mathrm{CH}$, nurses scaled longer in the other subunits remain a longer time without managing it.

The second aspect questioned is the nature of the training, especially for the need to develop clinical reasoning of nurses. The management of the technology requires the ability of interpretation, articulating the data sent by equipment to those generated by patients, given the pathophysiological condition. Therefore, nurses must link this knowledge through clinical reasoning, subsidizing their decision making.

There was a failure to better understand the physiological changes that may be happening to patients and all that. I think if we had specific training, we would better understand the changes the machine can bring to patients, what they are doing. We know the basics so I know the machine is ultrafiltering... but we need to know the dosage of calcium chloride, why I have to dosage [...] Why do I have to stop? Why is the patient using citrate? Why increase and decrease citrate? And the use of bicarbonate? It has a nephrological prescription, most people follow, but do not know why [...]. (C2: up to 5 years of training, up to 5 years in the sector, specialist in ICU)

The difficulties experienced in the daily practice of care for this patient lead to the negative evaluation of training, which is more present among the most recent professionals in the sector, with less than 3 years of operation, as is the case of $C 4$ and $C 12$.

It did not give me security. It did not give me a qualified contribution so that I felt prepared to run a machine by myself. (C4: up to 5 years of training, up to 5 years in the sector, not an ICU specialist)

It is concerning because when you are hired there is no effective training to handle the Prism in everyday work life, not always a Prism is smooth. The company does not give you a foundation, an effective training. (C12: up to 5 years of training, up to 5 years in the industry, specialist in ICU)

\section{Performance in the management of continuous hemodi- alysis: difficulties and risks of active failures}

The identified characteristics of the nurses' training result in the coping of difficulties when handling continuous hemodialysis, theme with $25 \mathrm{RU}$. Thus, these difficulties referred to the assembly of equipment, registry of configurations, alarms and clinical interpretation.

An example of management difficulties refers to the resolution of unexpected situations resulting from the use of continuous hemodialysis, such as the need to return blood to the patient or the calibration of the scales seen in the excerpts:

[...] One thing that often happens is the loss of calibration of the scales, when it disbalances the machine on the scale and not everyone is skilled to do so. And you end up having a bit of an upset because you end up having to call someone else to calibrate and sometimes you even have to change the machine because you cannot do it. (C6: 5-10 years of training, up to 5 years in the sector, not an ICU specialist)

l ended up in a mess, because the step by step for me is still hard on how to return [the blood] of the machine, I know the materials, this difficulty is punctual, the biggest is still to return, I cannot even get the step by step to return it. (C7: up to 5 years of training, up to 5 years in the sector, not an ICU specialist)

The data also indicates difficulties in the preparation stage of the system and parameter programming. This difficulty has to do with the understanding of information that is sent by the $\mathrm{CH}$ equipment, from which nurses direct their actions. This compromises the onset of continuous hemodialysis operation and the adjustments of its parameters during treatment, as it depends on this interpretation of the clinical response presented by the patient.

When you are installing the filter, sometimes you move it wrongly, you set an inadequate configuration. In the configuration the type of treatment is CVVHDF, but there are people who confuse because there is also CVV [... a and they end up interchanging them, which messes with every configuration and later they will have a problem, that it was there in the start configuration. (C2: up to 5 years of training, up to 5 years in the sector, specialist in ICU)

[...] At the time of putting the bag of citrate, the machine asked for a calculation, which nobody could do, and he ended up contacting the responsible person, and that person asked to reassemble, unload the kit to be able to reassemble the machine. (C13: up to 5 years of training, up to 5 years in the sector, not an ICU specialist)

Finally, another difficulty concerns alarms. This is because there are nurses who still cannot interpret their meaning to solve them, a fact that compromises their performance. It is seen that the report of these difficulties is greater among those who have up to 5 years of activity in the sector, even specialists in ICU.

The alarms, I have no idea what they are about; improper assembly; balance is not calibrated. I have many doubts in these items, but I try to perform the care in the best way I can, without causing the patient any damage [...] besides the mentioned return of the blood. (C16: 5-10 years of training, up to 5 years in the field, specialist in ICU)

I was trained to set up dialysis, look at the parameters before to prepare the dialysis bag, and change the bag, that's all! The maximum is to return the blood, but I do not know why it appears "negative access to the patient," which means that return. (C15: from 5-10 years of training, up to 5 years in the sector, specialist in ICU)

\section{DISCUSSION}

The data shows that nurses question their academic and professional training to work in ICU, specifically in the conduction of continuous hemodialysis, considering it insufficient to meet the demands of this area of performance. In addition, a portion of those investigated do not have graduate courses in Intensive Care or Nephrology, and even those with specialization in ICU, report not having a specific training for the management of the technology at hand.

This discussion about undergraduate training for the provision of intensive care has gained visibility, mainly due to the aging profile of the population, which results in the involvement of chronic-degenerative diseases, often leading to hospitalization 
and demand for ICU beds. Because of the lack of these vacancies, intensive care is nowadays increasingly being performed outside the ICU, since a share of these patients remain in clinical, surgical and emergency units ${ }^{(18)}$.

Faced with this reality, the critical patient's stay in non-critical units of hospitalization has raised the debate about nurses' training, especially when investigations indicate weaknesses of the training in the particularity of intensive care during the undergraduate course. It is the case of research, which described the profile of nurses, who work in two ICUs of a teaching hospital, in which it was found that some professionals had basic academic preparation, with minimum workload and little practice in ICU, which made it difficult their insertion in professional life when this first contact was intensive care ${ }^{(19)}$.

A second study analyzed the limits and possibilities related to the academic and professional training of nurses working at ICU ${ }^{(18)}$. The study included 25 ICU nurses from three hospitals, whose results were: $60 \%$ came from public institutions; only $24 \%$ reported that the discipline of Intensive Care was part of the curriculum; $24 \%$ have completed mandatory curricular training; $68 \%$ had specialization, of which $16 \%$ were specialists on Intensive Care. Regarding professional aspects, $60 \%$ of nurses say that there is no in-service training in the ICU that they work; $70 \%$ had difficulties at the beginning of their careers, which were associated with academic training at $96 \%{ }^{(20)}$.

This result shows that some institutions have excluded the discipline of Intensive Care, a fact that compromises the education process of general nurses regarding the principle of integrality, as well as the care provided by this professional. This is because there are links between the ICU team and care quality, that is, researchers in the field argue that ICU team training models impact the outcome of critical patients ${ }^{(21)}$.

This defense is supported by clinical trials which demonstrate that "high-intensity ICUs", whose patients are cared for by a fulltime intensivist, have lower mortality and length of hospital stay than "low-intensity ICUs", which have only elective consultations with an intensivist ${ }^{(21)}$.

The studies that support the discussion corroborate the results presented on the insufficiency of academic education regarding Intensive Care. This is seen when participants discuss their undergraduate nephrology knowledge, stating that they "are not trained during university," or that the "undergraduate course did not explain." In addition, it is emphasized that $\mathrm{CH}$ conducted with the participation of ICU nurses is not yet a reality in other institutions, becoming a novelty to those who come to act in the setting investigated. As a result, many nurses arrive at the unit only with knowledge acquired in undergraduation.

Therefore, this aspect should be considered by the institutions in the admission of nurses to work in these contexts, especially of newly undergraduate nurses with little experience, in the search for strategies to minimize these theoretical-practical gaps. In this direction, it is relevant to reflect on the way of insertion of professionals and the organization of continuing education about this assistance in continuous hemodialysis.

In the present study, in-service training is negatively analyzed by younger professionals, influenced by deficiencies in their training for Intensive Care. This is because, when working in an institution where ICU nurses act in $\mathrm{CH}$, they transfer the responsibility for filling the training gaps for the continuing education sector with regard to the provision of in-service training. Therefore, given their insecurity and the difficulties they face in handling continuous hemodialysis, they complain about the frequency of training and how it is developed.

The theoretical perspective of patient safety adopted in this research is systemic in nature, which means that error is multifactorial, and its underlying causes are sought. Therefore, one must consider the latent conditions that can lead to failures, to understand why and how errors occur, and to propose security barriers ${ }^{(13-14)}$.

It is considered that these failures are influenced by the work environment in which people are inserted and their organizational routines, which have repercussions on the thoughts and behaviors professionals have. In this understanding, many incidents begin in organizational processes that constitute latent failures, which are "transmitted" to the locus of action, creating the conditions for errors and violations ${ }^{(22)}$.

These conditions are of several orders and include technological and task factors; individual factors; team; work environment; organization and management; and institutional context. Organizational decisions about the use of temporary professionals, continuing education of professionals, training, supervision and availability of equipment are examples of decisions that generate the conditions for error ${ }^{(22)}$.

Under this perspective, the limitations in the academic and professional training evidenced in the data are then in a latent condition, which results in difficulties in the nurses' performance in the management of continuous hemodialysis, directly influencing patient safety.

When comparing this result with the analysis of the production of knowledge about $\mathrm{CH}$, it is seen that a part of international literature also situates the discussion about nurses' role in conducting the continuous hemodialysis in the ICU concerning the need for specialized knowledge and training. Thus, one of the lines of investigation problematizes the preparation of intensive care nurses for managing $\mathrm{CH}$, and there is no consensus about this practice ${ }^{(4,6,8-9)}$.

Such international literatures indicate a substantial lack of training for the staff involved with patients in $\mathrm{CH}$, many without any specific training, which interferes in the achievement of a professionals' high performance ${ }^{(4,8)}$. In one of these studies with professionals dealing with continuous hemodialysis in ICU, when asked about the problems of their practice, $31 \%$ answered lack of training ${ }^{(8)}$.

It should be emphasized that there are few field investigations focused on the practice of nurses in the management of $\mathrm{CH}$ articulated to patients' safety, especially at national level. However, when thinking about continuing education in ICUs in a generic way, a Brazilian study, which sought the perception of nurses at an ICU about how continuing education occurs, concluded that in the institution researched continuing education is generalist, is not based on the specificity of demands of Intensive Care, but occurs from the specific difficulties identified in the follow-up of the team's work ${ }^{(23)}$.

Thus, organization models of Nursing care, which are conducted with the participation of ICU nurses, require the implementation of effective educational strategies to guarantee the competence of these professionals, raising the analysis of in-service training regarding their periodicity, the encouragement of nurses' clinical 
reasoning and the need for simulated teaching, aiming to provide safety in their performance.

In the case of research, as this competence is still not consolidated, there are concerns about the impact of training in nurses' performance, seen in the report of $\mathrm{C} 15$, which analyzes the weaknesses of their education and how this can affect patients given the complexity of care on continuous hemodialysis. On the other hand, the difficulties identified in performing coagulation of the filter, where it is necessary to return the blood to the patient, to de-calibrate the scales of equipment or to interpret the meaning of the alarms are examples present in the data, which illustrate the potential repercussions on patient safety.

The interviewed nurses 6 and 7 said, respectively, that "not everyone is able to calibrate the scale" or that "they have not yet taken the step by step procedure for the return of blood". This is ratified by $\mathrm{C} 16$ who "does not know what the unbalanced scale alarm is about". Thus, these difficulties can result in loss of blood volume of patients, present in the circuit of $\mathrm{CH}$, considered an active failure from a safety perspective.

This shows the repercussions of training of ICU nurses in the safety of their performance in relation to critical patients in $\mathrm{CH}$. One study, which also reflects this impact, is the review of the notifications to the UK National Security Agency of safety incidents associated with equipment applied to critical patients. Of the 1,021 equipment-related incidents, the hemofilters accounted for 107 incidents ${ }^{(24)}$.

As for the damage level of hemofilter incidents, 49 had temporary damage (46\%) and 11 were potentially fatal (10\%); 45 of the 107 occurred due to incorrect use (42\%) and 37 due to equipment defect (35\%). In 10 incidents, incorrect use of the hemofilter was related to anticoagulation problems; and in 12, to the incorrect use of bicarbonate in the filtration fluid. The authors state that incidents related to misuse could be solved by better training the teams ${ }^{(24)}$.

In the light of the theoretical framework of research, the systemic approach to failures does not mean transferring the blame of those who are at the "tip" to managers, but it has a conceptual basis of analysis that considers all the factors that can contribute to the result. Therefore, mistakes should not be understood in isolation, a product of human fallibility, but considered in relation to the context in which people are inserted ${ }^{(22)}$.

When using this systemic analysis of incidents, it is intended to go beyond discovering the cause of incidents to explain to patients and their family what happened, but it constitutes a "window into the system", that is, it provides elements about the fragility of this system to look to the future, not the past, in order to make care safer ${ }^{(22)}$.

Regarding the fragility of the system studied, related to the insertion of professionals in the management of continuous hemodialysis with limitations in academic and professional training, as well as the way in which training occurs, it is necessary to think about training strategies of these professionals for the safety of their actions, as a barrier proposal. One of these refers to the training program created for ICU nurses to take care of patients in $\mathrm{CH}$. The training was conducted by the dialysis nurse, who worked full time training ICU nurses according to the learning needs of each one ${ }^{(25)}$.

The first part was theoretical, such as support of tools from the American Society of Nephrology and the application of weekly reviews and tests. The second, in a clinical setting as a dialysis nurse, and there was rotation in the areas that comprised dialysis to provide knowledge about patients with renal failure in acute scenarios. This model helps in the education of nurses to care for patients in Nephrology(25).

\section{Study limitations}

Few productions portray the experiences of ICU nurses in conducting continuous hemodialysis, limiting in the data analysis the comparison of the results and their significance.

\section{Contributions to the sector of Nursing}

Based on the data presented and on the theoretical framework of analysis, since the model of conducting $\mathrm{CH}$ in the unit is collaborative, of shared responsibility between ICU nurses and nurses of dialysis, it is recommended greater participation of nurses in the management of $\mathrm{CH}$, elaborating a program of accompaniment of inexperienced nurses.

This training program should allow the management of difficulties, the sharing of experiences and feelings experienced and the establishment of a learning environment, contributing to alleviate the difficulties in handling. In addition, it must consider the needs of newcomers, with simulation of practical situations, encouragement of clinical-diagnostic reasoning and development of the ability of critical analysis.

In view of the identified problems, of management of continuous hemodialysis, which brings repercussions to safety, it is convenient to think of using tools that can better guide the professionals to conduct these steps, minimizing questions and providing support for the accomplishment of this procedure, as is the case of the checklist.

Finally, it is necessary to review the curricular structure of undergraduate education to meet the demands of the aging population, which imply a greater demand for intensive care, requiring trained professionals. As for graduation courses, since half of all nurses are not ICU specialists, it requires encouragement for the specialty and the discussion with professors and researchers about the revision of their curricular structure, because these courses still do not account for this new demand of work for ICU nurses.

\section{FINAL CONSIDERATIONS}

The insertion of ICU nurses in the management of continuous hemodialysis, with weaknesses in training at undergraduation level and specialization on this handling, is a latent failure in the system studied. Such latent failure results in the risk of such professionals failing actively during the handling of $\mathrm{CH}$, especially newcomers, due to the difficulties identified during the return of the blood to the patient when filter coagulation occurs, in the calibration of scales, in the interpretation of alarms and in system programming.

Faced with this result, it is necessary to strengthen the institution's safety culture with strategies that lead individuals to worry about the potential risks and real failures arising from the use of continuous hemodialysis. In this understanding, to avoid that damage from errors reach the patient or mitigate the effects of 
errors, an organization of defensive barriers to promote the safety of critical patients is of utmost importance.

One of these barriers is the development of skills and competences about intensive care and the handling of continuous hemodialysis in newly admitted nurses through innovative learning experiences. This implies investing in the improvement of the in-service training program about the institution's continuous hemodialysis, aiming to improve the performance of professionals.

\section{REFERENCES}

1. Richardson A, Whatmore J. Nursing essential principles: continuous renal replacement therapy. Nurs Crit Care. 2014 Jan;20(1):8-15.

2. Allegretti AS, Hundemer G, Chorghade R, Cosgrove K, Bajwa E, Bhan I. Perspectives of continuous renal replacement therapy in the intensive care unit: a paired survey study of patient, physician, and nurse views. BMC Nephrology [Internet]. 2015 [cited 2016 May 31];16(105):1-8. Available from: http://bmcnephrol.biomedcentral.com/articles/10.1186/s12882-015-0086-5

3. Rewa O, Villeneuve PM, Eurich DT, Stelfox HT, Gibney RT, Hartling L, et al. Quality indicators in continuous renal replacement therapy (CRRT) care in critically ill patients: protocol for a systematic review. Syst Rev [Internet]. 2015 [cited 2016 May 31];30(4):102. Available from: https:// systematicreviewsjournal.biomedcentral.com/articles/10.1186/s13643-015-0088-1

4. Bourbonnais FF, Slivar S, Tucker SM. Continuous Renal Replacement Therapy (CRRT) practices in Canadian hospitals: Where are we now? Can J Crit Care Nurs. 2016;27(1):17-22.

5. Cabrera AR, Adame JLN, Almaráz JEL. Terapias continuas de reemplazo renal en pacientes críticos com lesión renal aguda. An Med Asoc Med Hosp ABC [Internet]. 2015 [cited 2018 Mar 12];60(2):110-117. Available from: http://www.medigraphic.com/pdfs/abc/bc-2015/bc152f.pdf

6. D'ávila M. La enfermera de UCl: pieza clave para el éxito de las técnicas depurativas continuas. Rev Enferm Intensiva [Internet]. 2012 [cited 2016 May 31];23(1):1-3. Available from: http://doi:10.1016/j.enfi.2011.12.002

7. Romero-García M, Cueva-Arizab L, Delgado-Hit P. Actualización en técnicas continuas de reemplazo renal. Enferm Intensiva [Internet]. 2013 [cited 2016 May 31];24(3):113-9. Available from: http://dx.doi.org/10.1016/j.enfi.2013.01.004

8. Ricci Z, Benelli S, Barbarigo F, Cocozza G, Pettinelli N, Di Luca E, et al. Nursing procedures during continuous renal replacement therapies: a national survey. Heart Lung Vessel [Internet]. 2015 [cited 2016 May 31];7(3):224-30. Available from: https://www.ncbi.nlm.nih.gov/pmc/ articles/PMC4593015/

9. Ellis K. Who should provide continuous renal replacement therapies? Nephrology nurses are better prepared to provide CRRT. Nephrol Nurs J. 2007;34(2): 228-9.

10. Sousa MRG, Silva AEBC, Bezerra ALQ, Freitas JS, Miasso Al. Adverse events in hemodialysis: reports of nursing professionals. Rev Esc Enferm USP [Internet]. 2013 [cited 2016 May 31];47(1):75-82. Available from: http://dx.doi.org/10.1590/S0080-62342013000100010. English, Portuguese.

11. Sousa MRG, Silva AEBC, Bezerra ALQ, Freitas JS, Neves GE, Paranaguá TTB. Prevalence of adverse events in a hemodialysis unit. Rev Enferm UERJ [Internet]. 2016 [cited 31 Jan 2018];24(6):e18237. Available from: http://www.e-publicacoes.uerj.br/index.php/enfermagemuerj/ article/view/18237/22139

12. Ministério da Saúde (BR), Agência Nacional de Vigilância Sanitária (ANISA). Resolução da Diretoria Colegiada n. 11 de 13 de março de 2014. Dispõe sobre os requisitos de boas práticas de funcionamento para os serviços de diálise e dá outras providências. Diário Oficial da União: República Federativa do Brasil; 2014. Mar 14, Seção 1: p. 40. (col. 3).

13. Reason J. Human errors: models and management. BMJ. 2000; 320(7237):768-70.

14. Reason J. Human error. London: Cambridge University Press; 2003. 318 p.

15. Golestaneh L, Richter B, Amato-Hayes M. Logistics of renal replacement therapy: relevant issues for critical care nurses.Am J Crit Care [Internet]. 2012 [cited 2016 May 31];21(2):126-30. Available from: http://ajcc.aacnjournals.org/content/21/2/126.short

16. Vaismoradi $\mathrm{M}$, Turunen $\mathrm{H}$, Bondas T. Content analysis and thematic analysis: implications for conducting a qualitative descriptive study. Nursing \& Health Sciences [Internet]. 2013 [cited 2016 May 31];15(3):398-405. Available from: http://onlinelibrary.wiley.com/doi/10.1111/ nhs.12048/full

17. Fontanella BJB, Luchesi BM, Saidel MGB, Ricas J, Turato ER, Melo DG. [Sampling in qualitative research: a proposal for procedures to detect theoretical saturation]. Cad Saúde Pública [Internet]. 2011 [cited 2016 May 31];27(2):389-394. Available from: http://dx.doi.org/10.1590/ S0102-311X2011000200020. Portuguese.

18. Zandomenighi, RC, Mouro DL, Oliveira CA, Martins EAP. Intensive care in hospital emergency services: challenges for nurses. Rev Min Enferm [Internet]. 2014 [cited 2016 May 31];18(2):404-414. Available from: http://www.reme.org.br/artigo/detalhes/936

19. Camelo SHH, Silva VLS, Laus AM, Chaves LDP. Perfil profissional de enfermeiros atuantes em unidades de terapia intensiva de um hospital de ensino. Ciênc Enferm [Internet]. 2013 [cited 2016 May 31];19(3):51-62. Available from: http://dx.doi.org/10.4067/ S0717-95532013000300006.

20. Pimentel TS, Lúcio IML, Oliveira KCPN, Bastos MLA, Santos EA. Working process of nurses of intensive care units: challenges of academic training. Rev Enferm UFPE Online [Internet]. 2013 [cited 2016 May 31];7(10):5915-22. Available from: http://www.revista.ufpe.br/ 
revistaenfermagem/index.php/revista/article/view/4227/pdf_3610

21. Courtright KR, Kerlin MP. Intensive care unit staffing and quality of care: challenges in times of an intensivist shortage. Rev Bras Ter Intensiva [Internet]. 2014 [cited 2016 May 31];26(3):205-207. Available from: http://dx.doi.org/10.5935/0103-507X.20140031

22. Vincent C. Segurança do paciente: orientações para evitar eventos adversos. São Caetano do Sul (SP): Yendis; 2009. 324 p.

23. Lazzari DD, Schmidt N, Jung W. Educação continuada em unidade de terapia intensiva na percepção de enfermeiras. Rev Enferm UFSM [Internet]. 2012 [cited 2016 May 31];2(1):88-96. Available from: http://dx.doi.org/10.5902/217976924592

24. Thomas AN, Galvin I. Patient safety incidents associated with equipment in critical care: a review of reports to the UK National Patient Safety Agency. Anaesthesia [Internet]. 2008 Nov [cited 2016 May 31];63(11):1193-7. Available from: http://onlinelibrary.wiley.com/ doi/10.1111/j.1365-2044.2008.05607.x/full.

25. Ford L, Santa-Teresa E. From critical care nurse to nephrology nurse in the intensive care unit. Nephrol Nurs J. 2013; 40(5): 451-455. 